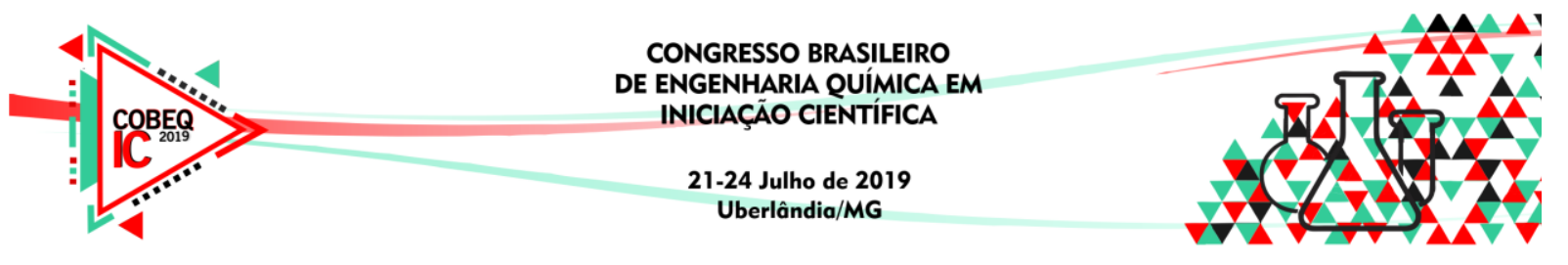

\title{
PRÉ-TRATAMENTO ORGANOSSOLVE DA BIOMASSA RESIDUAL DE EUCALIPTO USANDO GLICERINA BRUTA
}

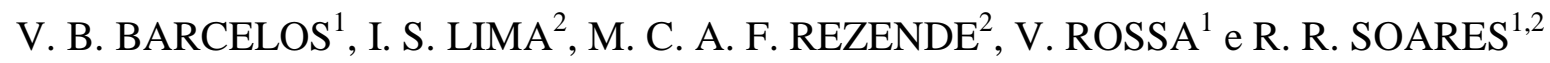 \\ ${ }^{1}$ Universidade Federal de Uberlândia, Faculdade de Engenharia Química \\ ${ }^{2}$ Universidade Federal de Uberlândia, Programa de Pós-Graduação em Biocombustíveis \\ E-mail para contato: vitorbabilonia@ hotmail.com
}

\begin{abstract}
RESUMO - Na busca por fontes alternativas de energia, a biomassa vem se destacando devido à sua abundância e versatilidade energética. Além da geração de energia através da queima, a biomassa lignocelulósica, composta principalmente por celulose, hemicelulose e lignina, também pode ser utilizada na produção de biocombustíveis e diversos produtos de interesse econômico, como por exemplo, produtos da lignina. Objetivando a separação dos componentes da biomassa para geração de produtos de valor agregado, realizou-se nesse trabalho o pré-tratamento organossolve da biomassa residual de eucalipto, utilizando como solvente a glicerina bruta, subproduto na produção do biodiesel. Foram definidas como variáveis para análise do processo, a temperatura, o tempo de reação e a concentração de glicerina bruta em água,. Após o pré-tratamento, obteve-se uma biomassa deslignificada (fase sólida), e uma fase liquida (licor negro) contendo a lignina extraída. Com uma etapa posterior de decantação ácida do licor negro, a lignina foi separada e quantificada. A partir de análise estatística, encontrou-se que os pré-tratamentos realizados em maior temperatura $\left(220^{\circ} \mathrm{C}\right)$ e concentração $(80 \%)$, apresentaram melhores extrações de lignina, obtendo como valor ótimo $11,25 \mathrm{~g}$ de lignina $/ 100 \mathrm{~g}$ de biomassa. O uso de resíduos no pré-tratamento e a obtenção da lignina podem viabilizar a realização do processo, pois geram redução de custos e produtos de interesse comercial.
\end{abstract}

\section{INTRODUÇÃO}

Resíduos da indústria florestal, setor com alto desenvolvimento e participação na economia do país, ainda possuem destinação pouco nobre. A maior parte dos resíduos da colheita florestal é deixada no campo (dificultando o trabalho de replantio) ou é queimada em caldeiras para produção de energia. Logo, o estudo do processo de pré-tratamento desses resíduos procura agregar valor ao material, o que segundo IPEF (2019), vem sendo buscado cada vez mais pelas empresas do setor.

O tratamento organossolve vem sendo utilizado a fim de romper estruturas lignocelulósicas da biomassa. Segundo Zhang (2016), os pré-tratamentos que utilizam solventes orgânicos podem ser uma ótima opção, pois apresentam vantagens relevantes, como a capacidade de fracionamento da biomassa em celulose, lignina e hemicelulose com alto teor de pureza, além do fato de que a recuperação e a reutilização dos solventes utilizados são processos simples e de fácil execução. O pré-tratamento consiste no processamento da 


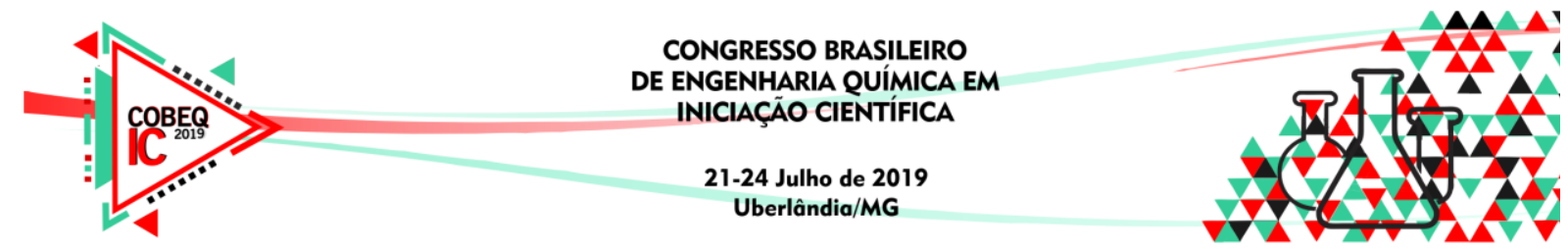

biomassa com um solvente orgânico como etanol e o glicerol, promovendo o fracionamento da biomassa. Após o processo, a celulose fica disponível na fase sólida (biomassa prétratada), livre da lignina, sendo possível sua posterior utilização, como na produção do etanol. (SANTOS, 2018). Já a lignina extraída da biomassa, é retida na fração liquida.

A lignina é um heteropolímero amorfo, composto por três moléculas de fenilpropano (Figura 1). Sua finalidade biológica é conferir rigidez à planta, impermeabilidade aos tecidos e prover resistência a ataques microbianos. Sua estrutura é amorfa, é um composto insolúvel em água e opticamente inativo. A lignina pode ser utilizada como combustível sólido para caldeiras, produção de resinas fenólicas, poliésteres, espumas de poliuretano, dispersantes, surfactantes, e pode ser material precursor para a obtenção de compostos fenólicos de baixa massa molecular (OLIVEIRA, 2016). Um esquema para os usos da lignina é representado na Figura 2 (adaptado de Schuchardt e Ribeiro, 2001).

Figura 1 - Monômeros da lignina

Figura 2 - Esquema para uso da lignina
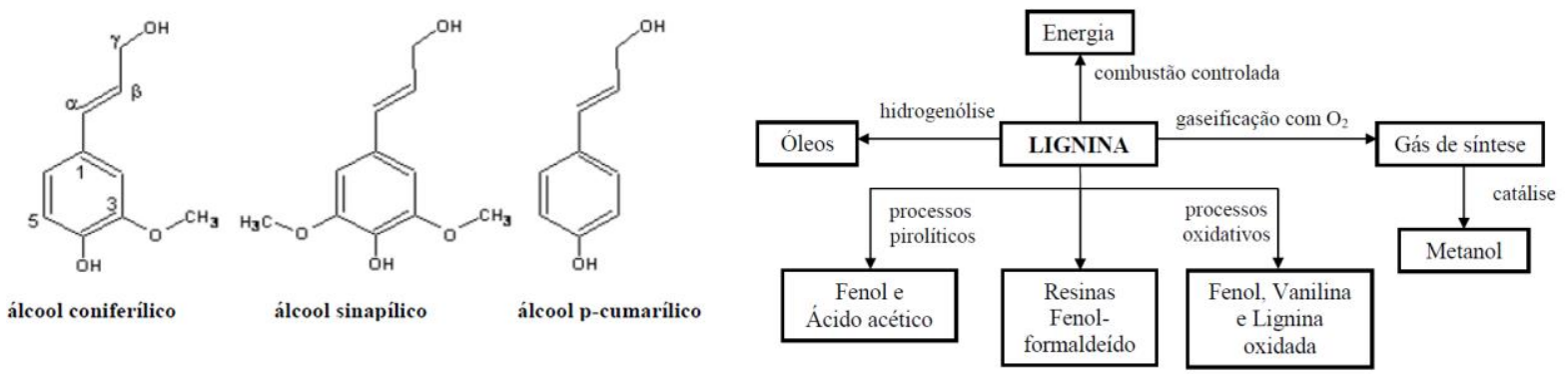

O glicerol, subproduto da produção do biodiesel é barato e produzido em grande quantidade no Brasil. Segundo a Agência Nacional do Petróleo (ANP), em 2016, foram gerados $341.911 \mathrm{~m}^{3}$ de glicerol no país, provenientes da fabricação do biodiesel. O glicerol não tratado obtido por esse processo é denominado glicerina bruta ou glicerina loira.

Nesse contexto, este trabalho tem por objetivo analisar o pré-tratamento organossolve da biomassa residual de eucalipto, utilizando como solvente a glicerina bruta. Para tanto, serão definidos os melhores parâmetros para realização do pré-tratamento, que levam à obtenção de produtos de valor agregado, justificando o processo e o tornando vantajoso.

\section{MATERIAIS E MÉTODOS}

\subsection{Biomassa Utilizada}

A biomassa de eucalipto utilizada no estudo foi cedida pela Lwarcel Celulose, e provém de rejeito de colheita florestal realizada pela empresa, para produção de celulose. A glicerina bruta utilizada foi cedida pela usina Caramuru, localizada em Ipameri-GO, sendo um subproduto da fabricação de biodiesel pelo processo de transesterificação.

A biomassa lignocelulósica passou por processo de secagem, foi homogeneizada para realização de análise granulométrica, utilizando-se diâmetro médio de partículas entre 20-28 mesh. Foi caracterizada a biomassa, tendo sido obtidos os teores em massa de 43,30\% de 


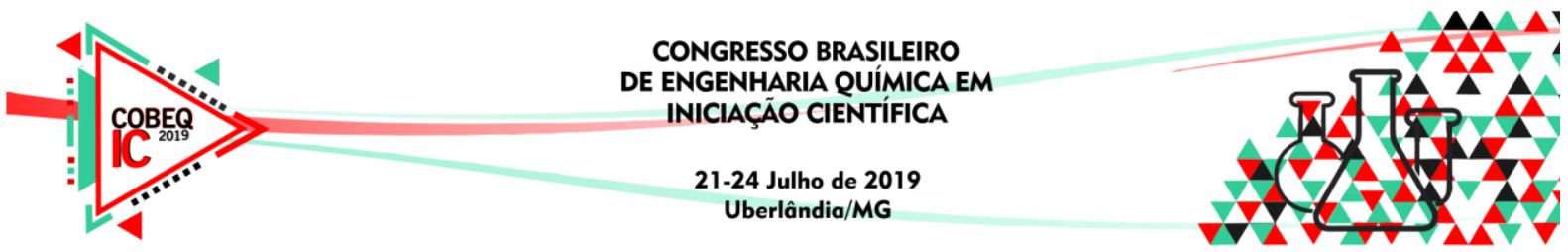

celulose, $13,40 \%$ de hemicelulose, $27,80 \%$ de lignina total, 5,90\% de umidade $1,10 \%$ de cinzas e 7,90\% de extrativos, segundo a norma TAPPI (1996, adaptada).

\subsection{Pré-Tratamento Organossolve}

O pré-tratamento foi realizado em reator batelada, utilizando volume total de $150 \mathrm{~mL}$, adicionando-se $5 \mathrm{~g}$ da biomassa de eucalipto e glicerina bruta em solução aquosa, em três diferentes concentrações. Após cada reação, o sistema foi resfriado em banho de gelo para que cessasse a reação, e filtrado para a separação das fases solida (biomassa pré-tratada) e liquida (licor negro). O licor negro foi armazenado para análise quanto aos seus componentes e extração da lignina. Foi utilizado um planejamento experimental $2^{(3-0)}$ para analisar a influência da temperatura, concentração de glicerina e tempo na extração de lignina.

\subsection{Extração da Lignina}

Após a obtenção do licor negro, foi realizada uma decantação ácida, tendo sido adicionados $5 \mathrm{~g}$ de licor negro, $10 \mathrm{~mL}$ de uma solução de $\mathrm{HCl}$ 0,3M, a fim de obter a lignina. Após preparo, os tubos foram tampados e levados à centrífuga, a uma rotação $4000 \mathrm{rpm}$, durante 40 minutos. As amostras foram então deixadas em repouso durante uma noite e, no dia seguinte, foi retirado o sobrenadante, e o precipitado seco em estufa a $50^{\circ} \mathrm{C}$ até massa constante, segundo o procedimento utilizado por Romaní et al (2016). Após essa etapa, foi quantificada a lignina extraída em cada experimento, e foi realizada análise estatística visando definir os melhores valores das variáveis significativas para o processo.

\section{RESULTADOS E DISCUSSÃO}

A Tabela 1 mostra a matriz planejamento experimental $2^{(3-0)}$ e os resultados obtidos para a extração de lignina.

Tabela 1 - Matriz do planejamento experimental $2^{(3-0)}-8$ experimentos com 3 repetições no ponto central para estudo da influência das variáveis: temperatura de reação, tempo de reação e concentração de solução aquosa de glicerina bruta na deslignificação da casca de eucalipto.

\begin{tabular}{|c|c|c|c|c|}
\hline Experimento & $\begin{array}{c}\text { Temperatura } \\
\left({ }^{\circ} \mathrm{C}\right)\end{array}$ & $\begin{array}{c}\text { Concentração } \\
(\%)\end{array}$ & $\begin{array}{c}\text { Tempo } \\
(\mathrm{h})\end{array}$ & $\begin{array}{c}\text { Extração (g lignina/100 g } \\
\text { de material) }\end{array}$ \\
\hline \hline 1 & $180(-1)$ & $40(-1)$ & $1(-1)$ & 3,8287 \\
\hline 2 & $220(+1)$ & $40(-1)$ & $1(-1)$ & 5,6678 \\
\hline 3 & $180(-1)$ & $40(-1)$ & $4(+1)$ & 2,9827 \\
\hline 4 & $220(+1)$ & $40(-1)$ & $4(+1)$ & 6,4163 \\
\hline 5 & $180(-1)$ & $80(+1)$ & $1(-1)$ & 5,5025 \\
\hline 6 & $220(+1)$ & $80(+1)$ & $1(-1)$ & 11,2469 \\
\hline 7 & $180(-1)$ & $80(+1)$ & $4(+1)$ & 6,4622 \\
\hline 8 & $220(+1)$ & $80(+1)$ & $4(+1)$ & 9,5600 \\
\hline 9 & $200(0)$ & $60(0)$ & $2,5(0)$ & 6,6500 \\
\hline 10 & $200(0)$ & $60(0)$ & $2,5(0)$ & 7,1800 \\
\hline 11 & $200(0)$ & $60(0)$ & $2,5(0)$ & 6,6800 \\
\hline
\end{tabular}




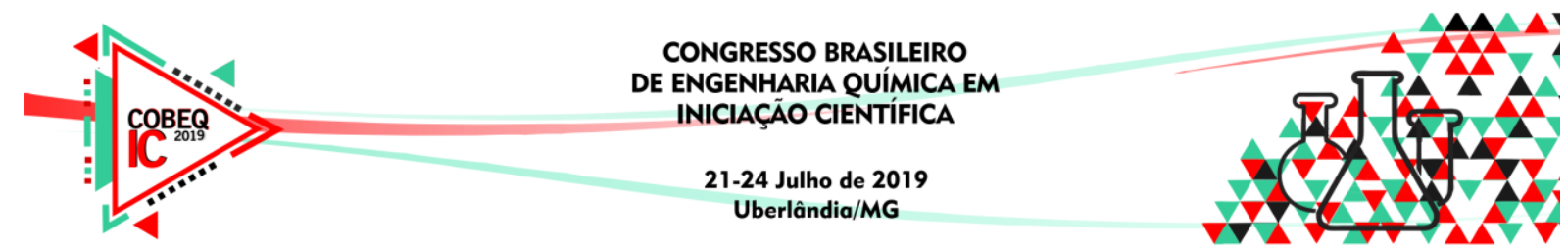

A unidade utilizada para a variável de resposta (Extração) dos valores obtidos foi gramas de lignina total/100 gramas de material biomassa seca. A partir dos valores de lignina extraída em cada experimento, foi realizada uma análise estatística dos dados obtidos no planejamento experimental $2^{(3-0)}$. Primeiramente, foi proposto um modelo quadrático com interações, porém verificou-se o modelo não foi significativo. Então, foi proposto um modelo linear para a análise dos resultados.

No tratamento dos dados obtidos pelo planejamento experimental $2^{(3-0)}$, os efeitos das variáveis temperatura $\left({ }^{\circ} \mathrm{C}\right)$, concentração de glicerol $(\%)$ e tempo reacional (h) foram analisados em relação à variável resposta: extração de lignina, utilizando o software STATISTICA 10.0 .

O gráfico de Pareto (Figura 2a) mostra os resultados dos efeitos estimados na análise estatística dos dados experimentais. As variáveis temperatura $\left({ }^{\circ} \mathrm{C}\right)$ e concentração de glicerol (\%) tiveram efeito significativo e positivo, enquanto a variável tempo de reação (h) não teve efeito significativo sobre a extração de lignina da biomassa. A Figura $2 b$ mostra a superfície de resposta, que relaciona a extração de lignina com as variáveis significativas (temperatura de reação e concentração da solução de glicerina).

Figura 2 - (a) Estimativa dos efeitos pelo gráfico de Pareto de acordo o planejamento experimental $2^{(3-0)}$; (b) Superfície de resposta que relaciona a extração de lignina com a temperatura de reação e concentração da solução de glicerina

(a)

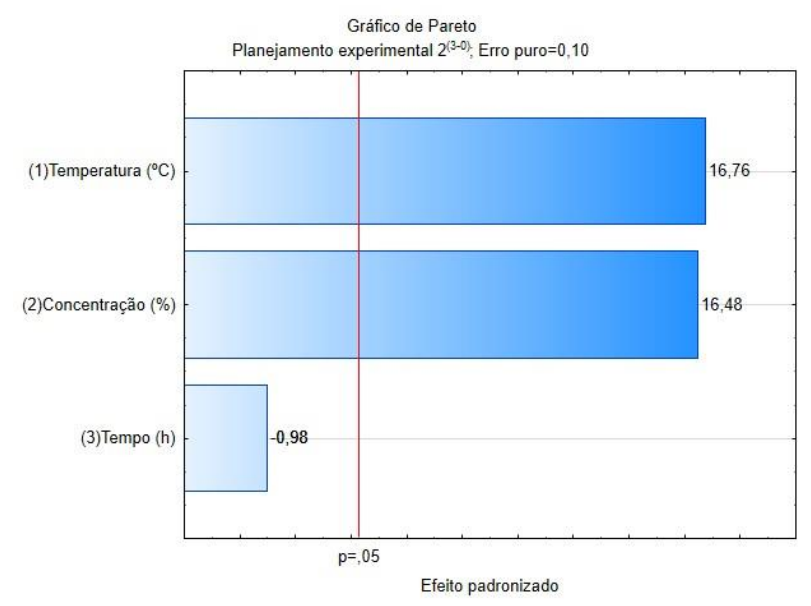

(b)

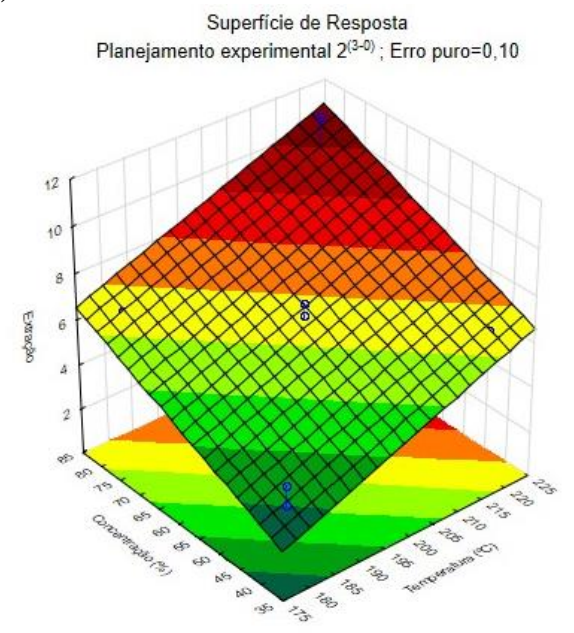

Após, foi realizada a regressão dos dados para obter um modelo matemático. A Equação 1 relaciona a extração de lignina com a temperatura de reação $(\mathrm{T})$ e a concentração de solução de glicerina (C). O coeficiente de correlação $\left(R^{2}\right)$ para este modelo é de 0,92, aproximadamente.

$$
\operatorname{Extração~}(\%)=0,09 * T\left({ }^{\circ} C\right)+0,09 * C(\%)-16,11
$$

Os maiores valores de extração foram obtidos aumentando-se a temperatura de reação e a concentração da solução de glicerina. Os maiores valores de lignina ficaram na região entre 


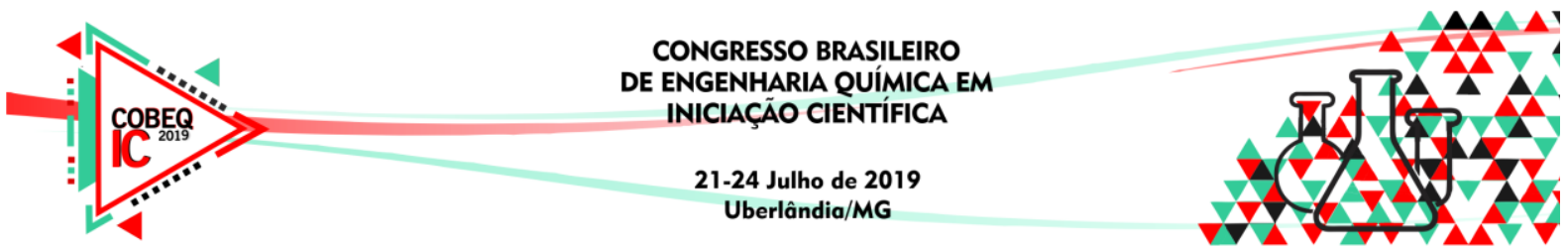

$9,56 \%$ e $11,25 \%(\mathrm{~m} / \mathrm{m})$, com temperatura de $220{ }^{\circ} \mathrm{C}$ e concentração de $80 \%$ de solução de glicerina.

As quantidades de lignina obtidas são um pouco inferiores às encontradas por Romani (2016), que obteve cerca de 15,6 g de lignina extraída por $100 \mathrm{~g}$ de casca de eucalipto, com condições de reação de $200{ }^{\circ} \mathrm{C}$, concentração de glicerol de $56 \%$ e tempo de reação de 56 min. Entretanto, o referido trabalho utilizou glicerina pura em solução, enquanto o presente trabalho utilizou glicerina bruta advinda da produção de biodiesel o que, em decorrência da presença de impurezas e outros contaminantes, pode ter afetado o rendimento da extração de lignina.

\section{CONCLUSÃO}

Após estudo e análise das variáveis utilizadas no pré-tratamento organossolve, concluise que as variáveis temperatura e concentração exercem efeito positivo sobre a extração de lignina da matéria vegetal, sendo que valores mais altos de temperatura e maiores valores de concentrações de solução de glicerina bruta aplicadas ao processo proporcionam melhores rendimentos para a extração de lignina presente na biomassa residual de eucalipto. Os maiores valores de extração de lignina encontrados encontram-se na região entre 9,56\% e 11,25\% $(\mathrm{m} / \mathrm{m})$, com temperatura de reação de $220^{\circ} \mathrm{C}$ e concentração de $80 \%$ de solução de glicerina. Verificou-se ainda que, nas condições estudadas, o tempo de reação não exerce influência significativa sobre a variável extração.

Sendo a lignina um produto de interesse comercial, sua obtenção pelo processo organossolve a partir de dois resíduos, mostra a eficiência e potencialidade de uso do prétratamento no conceito de biorrefinarias.

\section{REFERÊNCIAS}

IPEF (Instituto de Pesquisas e Estudos Florestais) - Anuário Estatístico da IBÁ (Indústria Brasileira de Árvore) 2018 - Ano Base 2017. Disponível em: https://iba.org/datafiles/publicacoes/relatorios/digitalsumarioexecutivo-2018.pdf. Acesso em 21/03/2019.

OLIVEIRA, C. A. P. Estudo do pré-tratamento do bagaço de cana-de-açúcar com ácido acético diluído em sistema pressurizado. p. 28-29, 2016.

ROMANÍ, A. et al. Valorization of Eucalyptus wood by glycerol-organosolv pretreatment within the biorefinery concept: An integrated and intensified approach. Renewable Energy, v. 95, p.19, 2016.

SANTOS, N. T. Avaliação do pré-tratamento do bagaço de cana-de-açúcar com glicerina. p. 30-32, 2018.

SCHUCHARDT, U.; RIBEIRO, M. L. A indústria petroquímica no próximo século: como substituir o petróleo como matéria-prima? Química Nova, v. 24, n. 2, p. 247-251, 2001.

TAPPI - Technical Association of The Pulp and Paper Industry. TAPPI test methods T264 om-88: "preparation of wood for chemical analysis". Atlanta: Tappi Technology Park, 1996, v.1. 


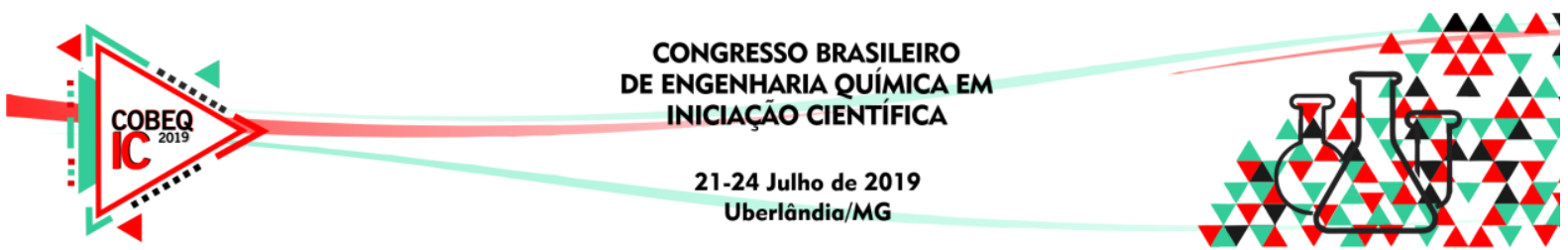

ZHANG K, PEI Z, WANG D. Organic solvent pretreatment of lignocellulosic biomass for biofuels and biochemicals: a review. Bioresour Technol. 2016; 199:21-33. 